\title{
Combining physical-based models and satellite images for the spatio-temporal assessment of soil infiltration capacity
}

\author{
Daniele Pedretti · Daniel Fernàndez-Garcia • \\ Xavier Sanchez-Vila • Marco Barahona-Palomo • \\ Diogo Bolster
}

Published online: 29 May 2011

(C) Springer-Verlag 2011

\begin{abstract}
The performance of managed artificial recharge (MAR) facilities by means of surface ponds (SP) is controlled by the temporal evolution of the global infiltration capacity $I_{c}$ of topsoils. Cost-effective maintenance operations that aim to maintain controlled infiltration values during the activity of the SP require the full knowledge of the spatio-temporal variability of $I_{c}$. This task is deemed uncertain. The natural reduction in time of $I_{c}$ depends on complex physical, biological and chemical reactions that clog the soil pores and has been observed to decay exponentially to an asymptotic non-zero value. Moreover, the relative influence of single clogging processes depend on some initial parameters of the soil, such as the initial infiltration capacity $\left(I_{c, 0}\right)$. This property is also uncertain, as aquifers are typically heterogeneous and scarcely characterized in practical situations. We suggest a method to obtain maps of $I_{c}$ using a geostatistical approach, which is suitable to be extended to engineering risk assessment concerning management of SP facilities. We propose to combine geostatistical inference and a temporally-lumped physical model to reproduce non-uniform clogging in
\end{abstract}

D. Pedretti $(\bowtie) \cdot$ D. Fernàndez-Garcia $\cdot$ X. Sanchez-Vila Hydrogeology Group, Department of Geotechnical Engineering and Geosciences, Technical University of Catalonia (UPC-BarcelonaTech), 08034 Barcelona, Spain e-mail: daniele.pedretti@upc.edu

M. Barahona-Palomo

Hydrogeology Group, Department of Geosciences, Institute of Environmental Assessment and Water Research

(IDAEA-CSIC), 08034 Barcelona, Spain

D. Bolster

Department of Civil Engineering and Geological Sciences, University of Notre Dame, Notre Dame, IN, USA topsoils of a SP, using field campaigns of local and large scale tests and additionally by means of satellite images as secondary information. We then postulate a power-law relationship between the parameter of the exponential law, $\lambda$, and $I_{c, 0}$. It is found that calibrating the two parameters of the power law model it is possible to fit the temporal evolution of total infiltration rate at the pond scale in a MAR test facility. The results can be used to design appropriate measures to selectively limit clogging during operation, extending the life of the infiltration pond.

Keywords Managed artificial recharge - Surface ponds · Infiltration capacity $\cdot$ Clogging $\cdot$ Collocated cokriging . Satellite images

\section{Introduction}

Managed artificial recharge (MAR) practices include several methods that aim to recover and enhance groundwater quality and productivity of depleted aquifers (Bouwer 2002). Among them, the use of excavated artificial ponds, or surface ponds (SP) are widely common (e.g. Management of aquifer and subsurface (2003), Scanlon et al. (2006)).

In an artificial SP facility, recharge is induced by flooding the excavation with water coming from any available source (e.g. reclaimed water, stormwater, river water), which percolates towards the subsurface by infiltration. In a properly designed facility, evaporation and other losses are typically negligible (Bouwer 1999) compared with the infiltration rates. The maximum rate at which water can infiltrate in the subsurface is known as the infiltration capacity $\left(I_{c}\right)$. It regulates both the total amount of infiltration towards the aquifer and some characteristic 
times (such as the water residence time within an SP) which are needed to make appropriate management of the facilities (Bouwer 2002; Pedretti et al. under review; Perez-Paricio and Carrera 1999).

Prediction of $I_{c}$ can be done at two characteristic spatial scales. At the pond scale, from a purely managerial perspective, the spatial average infiltration in the SP, $\bar{I}_{c}(t)$, provides quantitative information about the total amount of actual infiltration in an integrated way (Barahona-Palomo et al. 2010). Monitoring the SP facility during operation allows the evaluation of the integrated infiltration capacity with time. However, this does not provide any information about the spatio-temporal distribution of the local scale infiltration capacity $\left(I_{c}(\mathbf{x}, t)\right)$, which is crucial for the optimal operation, management, and maintenance $(\mathrm{O} \& \mathrm{M})$ of the artificial SP facility (Pedretti et al. under review).

Assessing the full spatio-temporal distribution of $I_{C}(\mathbf{x}, t)$ during operation is not realistically feasible. During recharge processes, $I_{c}$ reduces in time because of a variety of processes that tend to modify the pore size distribution (PSD) of the ground, namely reducing the porosity of the top soil (e.g. Bouwer 2002). The topsoil hydraulic conductivity $K_{s}(\mathbf{x}, t)$ depends on the PSD, which in turn con-
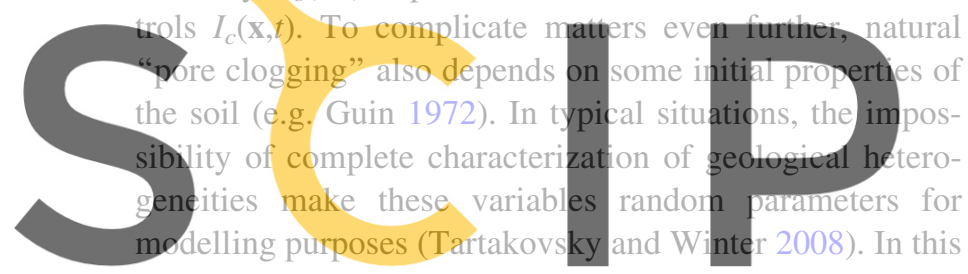

sense, a probabilistic approach is advisable (Krzysztofowicz, 2001), since it could then be integrated, into a larger

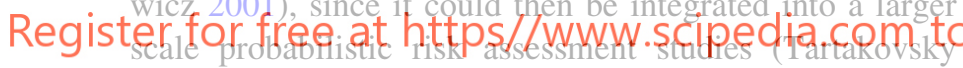
2007; Bolster et al. 2009; de Barros and Rubin 2008; Masetti et al. 2009).

In this work we explicitly exclude accidental extreme events (with very low frequency/probability) that suddenly reduce global infiltration (e.g. Bedford and Cook 2001, pp. 103-104). Natural reactions, on the other hand, are more frequent and are related to a variety of physical, biological and chemical mechanisms (e.g. Baveye et al. 1998; Vandevivere et al. 1995; Greskowiak et al. 2005) that together reduce $I_{c}$ during artificial recharge. As a consequence, the rate of natural clogging mechanisms at small scales is highly uncertain. Several approaches have been suggested in the past to assess the effect of independent individual mechanisms. For instance, the soil can be conceptualized as a natural filter in which suspended particles circulate in the soil while percolating; they are attracted and collapse into the pore spaces. At some macroscopic scale, this effect is called "physical clogging" and has been modeled using "depth filter" theories (see Zamani and Maini 2009; Pedretti et al. under review; Guin 1972 for details). A significant point is that the capacity of the soil to retain the particles (i.e. the potential of the soil to be clogged) depends on whether surface forces or volumetric forces dominate. Bioclogging can also be modeled using a macroscopic approach considering the expansion of microbial colonies to create a biomass that get trapped because of similar forces that affect non-organic particles (Baveye et al. 1998; Vandevivere et al. 1995; Clement et al. 1996).

The big question, however, remains how to evaluate the effect on pore clogging that encompasses the mutual dependence of all clogging mechanisms. Although several published field and laboratory experiments exist that aim to understand and quantify their mutual interaction depending on soil type (Perez-Paricio and Carrera 1999; Kim et al. 2010; Hoffmann and Gunkel 2010), predicting the clogging rates via cumulation of individual mechanisms remains, in the practice, challenging. The reasons are that: (i) reactions leading to a (macroscale) clogging effect take place at microscales (e.g. Baveye et al. 1998) that cannot be easily measured, or that cannot be easily upscaled to the field pond scale and (ii) the rate at which clogging mechanisms jointly develop depends on a variety of site-specific conditions and factors, such as textural heterogeneities of the soil (e.g. pore or grain size distributions-PSD/GSD)

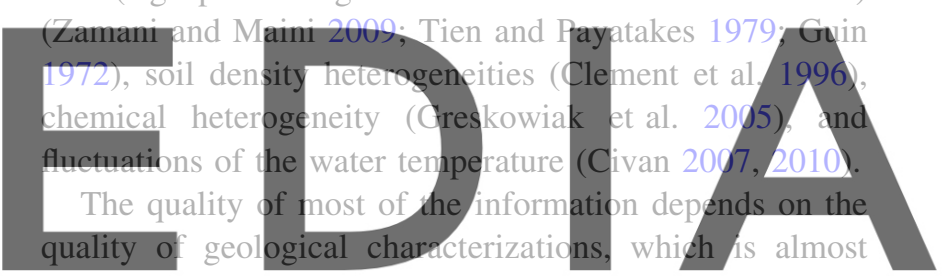
always poor in practice since direct investigations are costly, affected by serious errors and sometimes simply not dexvileag the versign weth put the waternark

correlate initial hydraulic conductivity profiles with the intensity of clogging. Unfortunately, most of them are based on assumptions of homogeneities that over- or underestimate the rate of clogging. For instance, assuming the soil pore sizes or the grain sizes to be uniformly (e.g. Kozeny 1927; Carman 1938; Hazen 1882) and non-uniformly (e.g. Guin 1972) distributed is essential to correctly estimate the development of clogging. Indeed, the use of uniform formulations implicitly include average macrocharacteristic features of PSD and GSD, such as the total soil porosity $\phi$ or some characteristic grain size $d_{g}$, from which the seepage velocity is calculated. However, bioclogging does not grow uniformly but rather starts by developing local microcolonies within smaller pores, and grows to occupy the larger pores. On the other hand, physical mechanisms act differently. According to the filter theory (see Zamani and Maini 2009; Pedretti et al. under review; Guin 1972 for details) the clogging rates are inversely proportional with $d_{g}$ but this relationship depends strongly on other factors such as the suspended solid size $\left(d_{s}\right)$ and $I_{c}(t=0)$. Guin (1972) adopted a macroscopic 
Kozeny-like model where the porous medium is decomposed into a bundle of channels with different hydraulic radii $R$ (ratio between porosity and the specific surface area of the soil, $S_{a}$ ). In the case of rapid particle deposition, the clogging rate of individual pores is proportional to the square of its specific surface area $\left(-\frac{\mathrm{d} S_{a}}{\mathrm{~d} t} \propto S_{a}^{2}\right)$. Thus, this implies that the area of larger pores (i.e. larger initial infiltration capacities) is decreased preferentially. In the case of slow particle deposition, $-\frac{\mathrm{d} S_{a}}{\mathrm{~d} t} \propto S_{a}^{1 / 2}$. Experiments on bioclogging (Cunningham et al. 1991; Vandevivere and Baveye 1992) showed that the relative change of permeability $\left(K_{s} / K_{s 0}\right)$ depends, among other parameters, on the GSD.

It has been observed that all clogging mechanisms do not go on indefinitely, but rather end up providing an asymptotic infiltration value, which varies in space (e.g. Baveye et al. 1998). The reasons that lead to an asymptotic clogging effect are controversial and depend on local conditions. For instance, bioclogging mechanisms roughly follow a Monod behavior (Monod et al. 1965; Matsumoto 1979; Baveye et al. 1998), which reproduce a microbial growth with a maximum asymptotic value of development. Physical clogging, on the other hand, varies in time since the governing forces change from volumetric to surface and vice-versá depending reactive surface areas, etc. (see phy pere description or whore physical pr ical clogging could theoreticta tion, biogging may help nreventing additional phys-

ical clogging, so that the combination of both processes

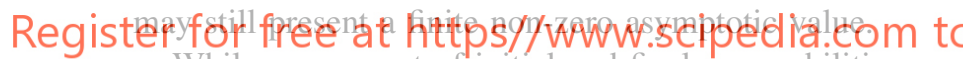
While assessment of initial and final permeabilities can certainly be done with the use of empirical or theoretical formulations, the question still remains about how to evaluate the actual evolution of infiltration with time. This is required for a proper risk assessment (Pedretti et al. under review). Lumped solutions such as exponential decay formulations are often adopted at the field scale (Iwasaki 1937; Perez-Paricio and Carrera 1999; Kim et al. 2010; Hoffmann and Gunkel 2010). The use of such models is appealing since only a few parameters are required for estimation purposes, but so far there is no widely accepted work on the relationship between the upscaled and the local infiltration models. While lumped (upscaled) models are routinely used as a way to assess when maintenance operations should take place at the full pond (usually drying the pond and cleaning), we contend that a detailed clogging model could be used to derive an ad-hoc remediation operation that targets only specific portions of the pond (similar to the concept of precise agriculture).

A major limitation of mapping infiltration variations locally in space and time is that primary information is limited and plagued by errors. A viable option to enhance the mapping of characteristic soil properties is to combine direct (primary) with secondary data (related to the primary ones). An example is to combine measurements from surface infiltrometers with satellite-images-based secondary information (Pedretti et al. 2010). Normally, secondary information is suitable for spatial assessment as it typically contains a denser dataset (e.g. Gooverts 1997), but the robustness of the method relies in the strength of the correlation existing between the two types of information.

In this paper, we develop a geostatistical approach to map soil clogging parameters integrating a limited dataset of direct information with secondary information based on satellite images. A physically-based model is used to evaluate the spatial-temporal decreasing of the local infiltration capacities throughout the SP.

The paper is structured as follows. In Sect. 2 we propose a local infiltration model with an exponential decay to an asymptotic value. Initial, asymptotic infiltration, and decay coefficients are considered to be correlated. In Sect. 3 we further develop the model by applying it directly to an artificial infiltration pond where local infiltration data is available at a few points and can be further obtained from a

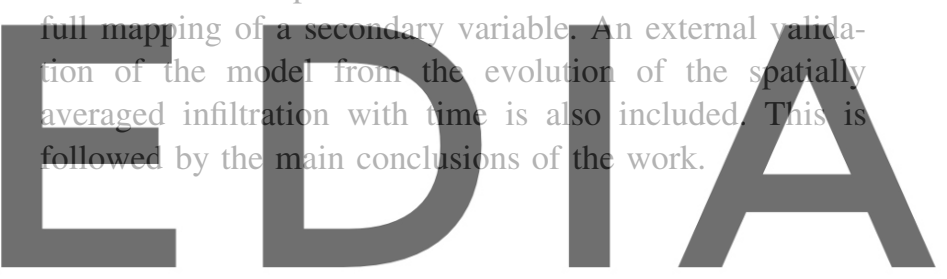

\section{dowallod dognte version without the watermark}

\subsection{Problem statement}

Let us consider a given artificial SP recharge site in which direct measurements of the local infiltration rate, $I_{c}(\mathbf{x}, t)$, are known at sparse locations and at a few discrete times, i.e., $I_{c}\left(\mathbf{x}_{i}, t_{j}\right)\{i=1, \ldots, m\},\{j=1, \ldots, n\}$. This is often the case in most practical applications as the operation of an artificial recharge pond is typically done under flooding conditions and thereby any exhaustive characterization of the infiltration capacity is too costly and time-consuming. The support scale of the measurement is local and given, for example, by the size of an infiltrometer test.

We assume that an extensively sampled secondary variable is available at some support scale. An example would be data coming from the colour intensity of a satellite image, which can provide valuable information related to the soil hydraulic properties such as the moisture content of the soil, the vegetative canopy density on the ground (Chica-Olmo and Abarca-Hernandez 2000; Granger 2000; Milewskia et al. 2009) or the infiltration capacity at a 
specific time (Pedretti et al. 2010). Evidently, a limitation of satellite images is that image-based methods are restricted to non-flooded times, with at most two measuring times, i.e., before and after flooding.

Under these conditions, we attempt to map the temporal evolution of the infiltration capacity at the site so that better management of the artificial recharge pond can be undertaken.

\subsection{Clogging model}

We assume that the temporal reduction of the infiltration capacity at every point $\mathbf{x}$ in the domain due to clogging processes follows a decaying exponential law. The model assumes that clogging takes place on the order of tens of days. Temperature can therefore be neglected as it fluctuates on two temporal scales, seasonally and daily, that do not affect clogging occurrence. Seasonality occurs at temporal scales much longer than clogging time, and night-day fluctuations are too short to affect clogging development permanently. The clogging model can be formulated in different ways. One possible formulation is
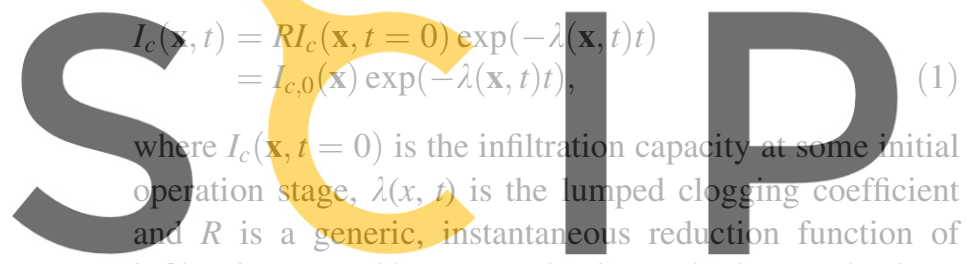

infiltration caused by gas production and other mechanisms (Olsthoorn 1982; Bpuwer 2002), which in general is close

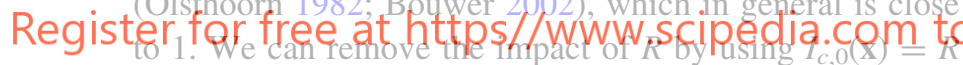

$I_{c}(\mathbf{x}, t=0)$ as the initial infiltration value. It is worth noting that in (1), $\lambda$ changes over space and time, tending to zero as time increases. Consequently, $I_{c}(\mathbf{x}, t)$ values tend to an (spatially dependent) asymptotic value, $I_{c, f}$.

Therefore, an alternative model to (1) that implicitly includes this asymptotic value $I_{c, f}$ can be formulated as

$I_{c}(\mathbf{x}, t)=I_{c, f}(\mathbf{x})+\left(I_{c, 0}(\mathbf{x})-I_{c, f}(\mathbf{x})\right) \exp (-\lambda(\mathbf{x}) t)$,

where $\lambda(\mathbf{x})$ is now constant in time. This clogging model constitutes the basis of our approach to map the temporal evolution of the infiltration capacity. The fundamental advantage of this model is that parameterizes the temporal evolution of the infiltration capacity $I_{c}$ by means of three constant-in-time variables/parameters: $I_{c, f}(\mathbf{x}), I_{c, 0}(\mathbf{x})$, and $\lambda(\mathbf{x})$, all three variable in space, and are therefore susceptible to simple geostatistical analysis.

Total infiltration capacity can be obtained by spatial averaging of either (1) or (2); i.e.

$\bar{I}_{c}(t)=\frac{1}{V} \int_{V} I_{c}(\mathbf{x}, t) d \mathbf{x}$.
In most cases $\bar{I}_{c}(t \rightarrow \infty) \equiv \bar{I}_{c, f}$ will be too small to be acceptable; that is, it will be below a pre-specified threshold value, $I_{t}$. Such small could be unacceptable in practical situations. Thus, the need for a model that can provide information about the spatial evolution of infiltration with time. It turns out that whenever $I_{c, f}(\mathbf{x})$ and $I_{c, 0}(\mathbf{x})$ are fully known, the temporal evolution of the local infiltration depend exclusively on $\lambda(\mathbf{x})$. We postulate that this non-time dependent clogging factor is directly correlated with some initial property of the soil, so that $\lambda(\mathbf{x})=f$ $\left(I_{c, 0}(\mathbf{x})\right)$. This is feasible since clogging develops at different rates according with the local distribution of PSD or GSD, both highly uncertain.

\subsection{Mapping the soil infiltration capacity}

If experimental measurements of $I_{c}$ are limited to a few locations, secondary information can be incorporated to estimate the spatial distribution of the primary variable. For this purpose, several geostatistical techniques can be used, such as the collocated cokriging model. Yet, in this case, its direct application is cumbersome as one needs to estimate

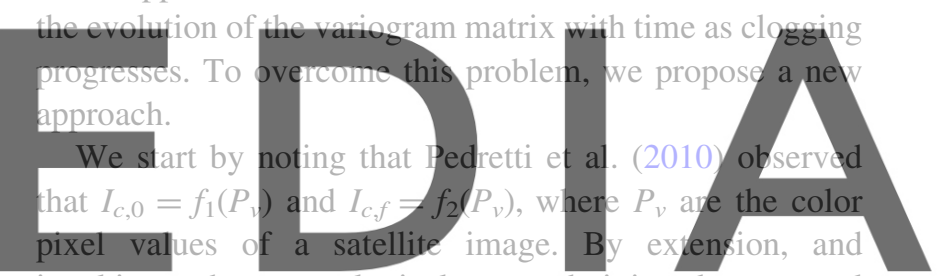

invoking a phenomenological approach, it is to be expected that there could exist a relationship between soil paramedrwalpad the verisiqe without the watermark

This relationship should be constructed via theoretical or empirical methods. The theory suggests that some clogging mechanisms, such as physical clogging, can be modeled using a filter approach (e.g. Zamani and Maini 2009; Pedretti et al. under review); thus, the clogging rate should be negatively correlated with some grain size representative diameter, $d_{g}$. Other mechanisms however do not necessarily rely on this assumption: biological clogging can be modeled using Monod-based growing models (e.g. Clement et al. 1996), for which the rate of bioclogging is linearly proportional to the soil density $\rho$ which is positively correlated with $d_{g}$ (Pedretti et al. under review). Therefore, in a real site, it is important to assess the relative importance of the two mechanisms, since this will control the relationship existing between $\lambda$ and the soil properties. In the field though, the use of (2) gives lumped clogging factors, in which the single effects of each mechanism is somehow hidden. As such, any relationship existing between $P_{v}$ and experimentally-based $\lambda$ does not give any indication of the relationship existing between $P_{v}$ and all the parameters characterizing the soil, including $d_{g}$, but 
also density, fraction of organic matter, etc. Thus, it is not a priori clear whether $\lambda$ and $P_{v}$ should be positively or negatively correlated. In the application example later we will use both possibilities.

Our approach starts from having a perfect knowledge of some secondary variable (obtained for example from satellite images), while there is little to no information on the three primary variables controlling infiltration: $I_{c, 0}, I_{c, f}$, and $\lambda$. Thus, it is possible to use some geostatistical approach involving either cokriging (to get a smooth estimate in a mean sense) or cosimulation (to be included in a Monte Carlo approach). Since data from the primary variables are always expected to be less than exhaustive, we chose a collocated cokriging approach under the Markov model I. Such a model limits the secondary variable to the data available at the estimation location, and further estimates the cross-variograms by employing an underlying regression model. The advantage is that matrix instabilities caused by densely sampled secondary data (such as high-resolution satellite rasters of pixel values) are avoided and reduce the burden of modelling all variograms and cross-variograms in a cokriging system (Almeida and Journel 1996; Journel 1999). In this case, the cokriging model only requires the knowledge of the variogram of the primary
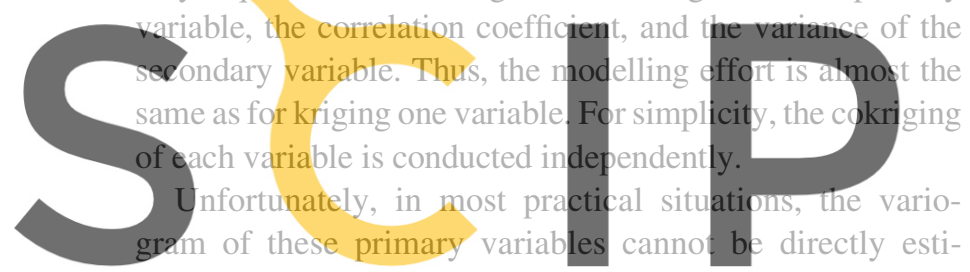

mated as too little information is available at a given SP site. To circumvent this problem, we suggest to completely

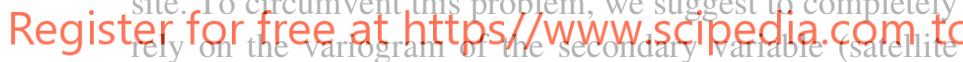
image) that is always well characterized. For each primary variable, $\left\{I_{c, 0}, I_{c, f}, \lambda\right\}$, the auto-variogram can be estimated using regression models. Pedretti and others (Pedretti et al. 2010) found that a linear regression satisfactorily correlates the natural logarithm of infiltration capacities (both $Y_{0}=$ $\ln \left(I_{c, 0}\right)$ and $\left.Y_{f}=\ln \left(I_{c, f}\right)\right)$ with the color pixel values of an image $\left(P_{v}\right)$. The model has the form

$$
\begin{aligned}
& Y_{0}=a_{0}\left(P_{v}\right)+b_{0}+\varepsilon_{Y, 0}, \\
& Y_{f}=a_{f}\left(P_{v}\right)+b_{f}+\varepsilon_{Y, f},
\end{aligned}
$$

where $a$ and $b$ are the regression coefficients, and $\varepsilon_{Y}$ represents regression model errors. To complete the picture we must specify a model for $\lambda$. Parsimony leads us to postulate a similar linear model in terms of $Y_{\lambda}=\ln \lambda$,

$Y_{\lambda}=a_{\lambda}\left(P_{v}\right)+b_{\lambda}+\varepsilon_{Y, \lambda}$.

From these simple models we can write the variogram functions as

$\gamma_{Y_{i}}(\mathbf{h})=a_{i}^{2} \gamma_{P_{v}}(\mathbf{h})+\gamma_{\varepsilon_{Y, i}}(\mathbf{h}), \quad i=0, f, \lambda$ where $\mathbf{h}$ is the lag distance between data values. We can further assume that the regression model errors are uncorrelated both with errors at different locations or with the secondary variable (pure nugget).

Once the spatial distributions of the three variables have been obtained, it is possible to use (2) to obtain the spatiotemporal distribution of the local infiltration rate, and consequently the temporally variable global infiltration. We now illustrate the method and highlight the limitations in a real site.

\section{Application example}

A pilot SP is located in Sant Vicenç dels Horts, close to the city of Barcelona (Spain). The geological background is a sequence of deltaic deposits of the river Llobregat. A high resolution image was captured in November 15, 2007 (Fig. 1), representing the ground conditions at the site before a flooding experiment was conducted. We will consider this as the initial state of our system, from which we wish to obtain a map of $I_{c, 0}$ values. The resolution of the image is around $0.5 \mathrm{~m}^{2}$ per pixel. The infiltration area is

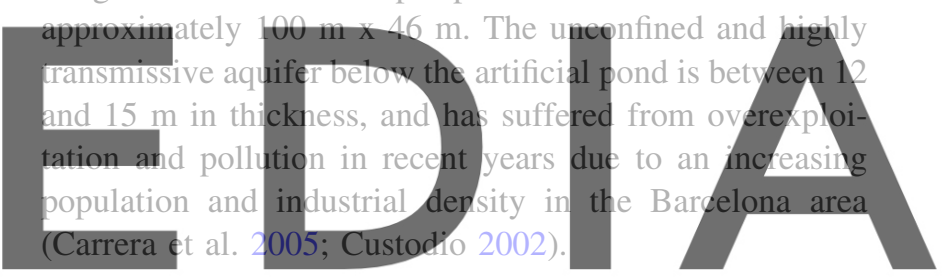

3.1 Observations and modelling at the pond scale

\section{downlgad the version without the watermark}

A flooding test was performed between March and June 2009 in order to test the performance of the site for MAR operations. The following variables were recorded on a continuous basis: headwater at the pond, $h(t)$; discharge rate towards the aquifer, $Q_{I N}(t)$ (recorded from water mass balance within the pond, disregarding evaporation); infiltration area, $A(t)$ (usually a direct function of $\mathrm{h}(\mathrm{t})$ to include the basin slopes); and distance from the surface to the water table, $L(t)$. Infiltration at the full pond scale is then obtained as

$\bar{I}_{c}(t) \approx\left(\frac{Q_{I N}(t) L(t)}{A h(t)}\right)$

The recorded infiltration values can be matched by a simple exponential model

$\bar{I}_{c}(t)=\bar{I}_{c, f}+\left(\bar{I}_{c, 0}-\bar{I}_{c, f}\right) \exp \left(-\lambda^{e} t\right)$

Figure 2 shows that a good match between data and the best-fit approximation of the large-scale infiltration model 
Fig. 1 Satellite image of the Sant Vicenç dels Horts EAP, close to Barcelona (property of Google and ICC, 2007). S-tags refer to the locations of infiltrometer tests; C-tags are excavated pits to observe the local geological stratigraphy

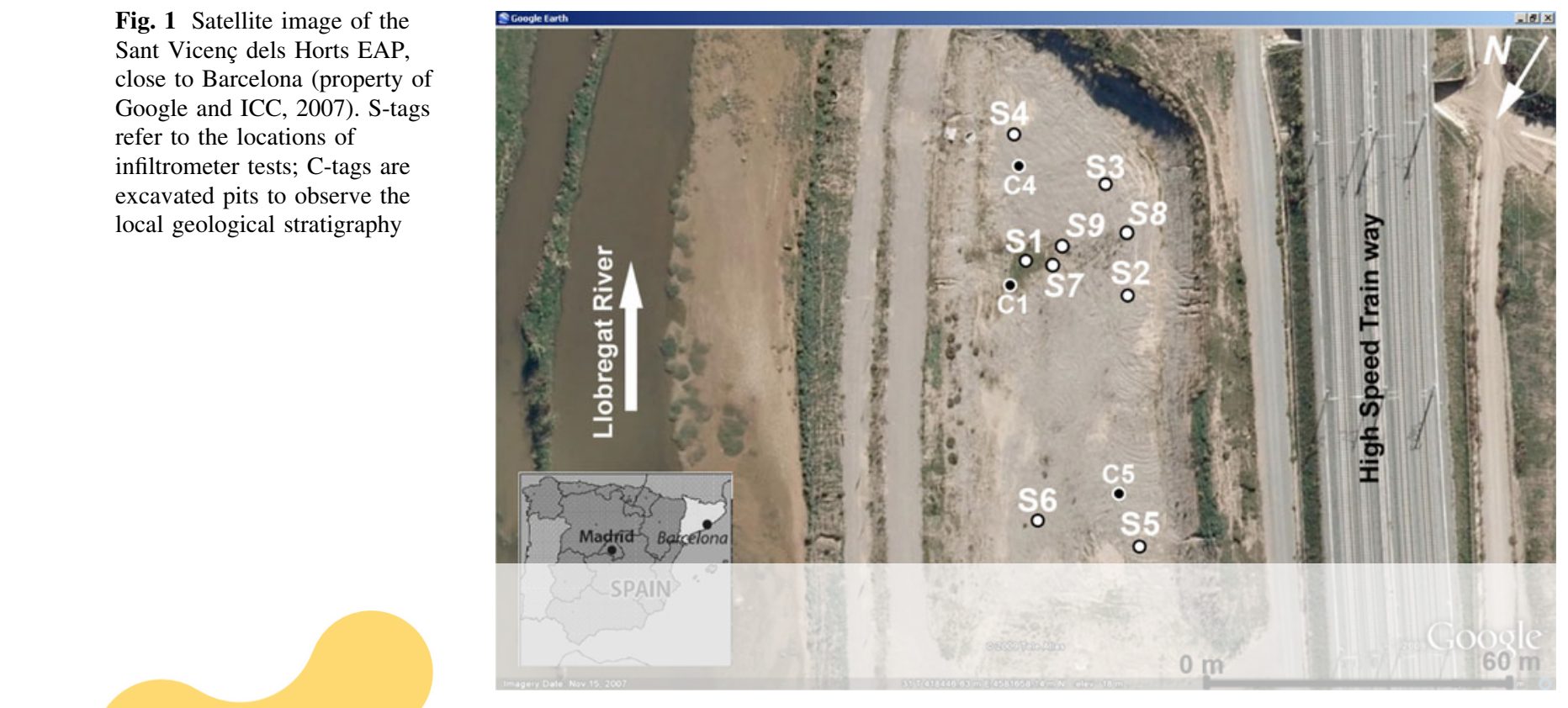

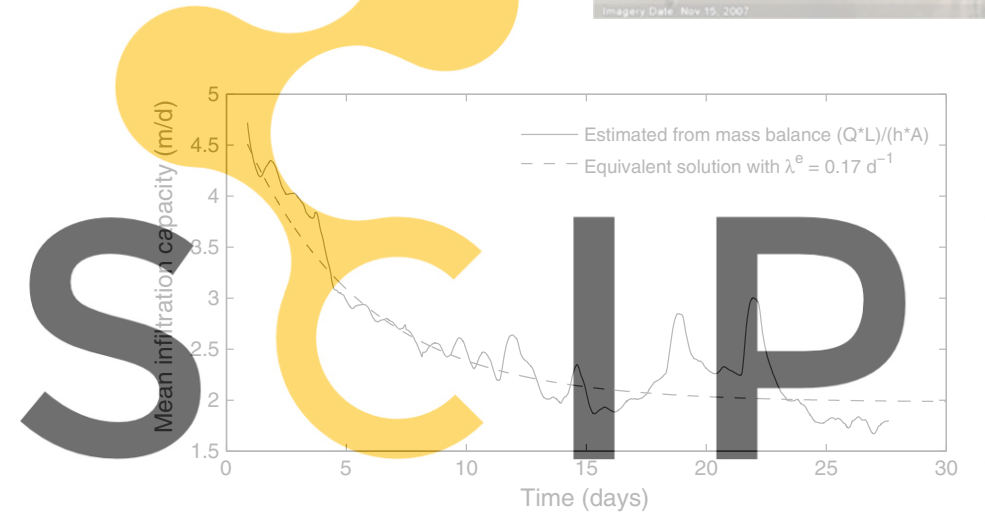

Register for frea at https//wwy scipedia,com to flooding test. The dotted curve is the best-fit approximation with $\bar{I}(t=$ $\infty)=1.98 \mathrm{~m}, / \mathrm{d}$ and $\lambda^{e}=0.17 \mathrm{day}^{-1}$

(9) can be obtained. $\lambda^{e}$ is an equivalent clogging parameter for the entire pond. Note that the asymptotic value is used to evaluate the minimum infiltration value of the pond, which is reached when clogging no longer develops. The solid line represents observations using (8), while the dotted line is the best fit model solution using (9) with the following parameters: $\bar{I}_{c, 0}=5.35 \mathrm{~m} / \mathrm{d}, \bar{I}_{c, f}=1.98 \mathrm{~m} / \mathrm{d}$, and $\lambda^{e}=0.17 \mathrm{day}^{-1}$.

Note that according to the calibration process using (9), we have a global model of the reduction of infiltration with time, that could now be used for management or risk evaluations. For example, it is found that reduction of infiltration to $50 \%$ of the initial value is reached after just roughly 7 days, but it will for example take 14 days to reduce to $40 \%$ of the original value. It is possible to obtain a compromise between allowing the system to work for larger periods without maintenance by just allowing less water to infiltrate.
In Fig. 2 the infiltration curve displays some daily oscillations. This is due to unaccounted causes, such as the

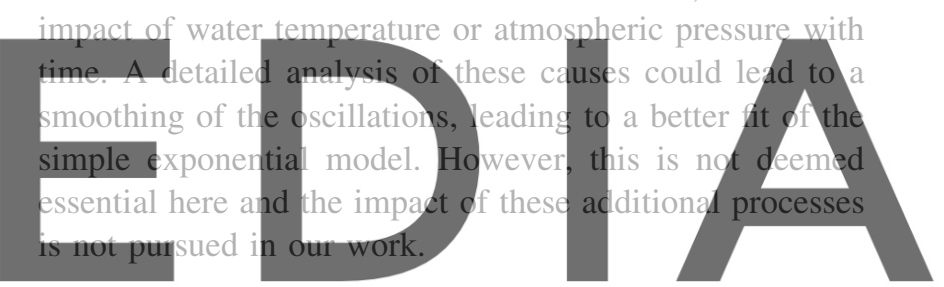

3.2 Observations at the local scale

\section{download the version without the watermark}

Double-ring infiltrometers (Smith 1972) were used to measure the local infiltration capacities at sparse locations in the SP, before and after the flooding test was performed. A double-ring infiltrometer reproduces the local soil transition from unsaturated to saturated conditions that would take place under flooding conditions, and evaluates the infiltration capacity. In short, two metal rings are buried a few centimeters deep into the soil and filled with water (at constant or variable height). After a standard time of two hours, the infiltration rate approaches a steady state value, identified as $I_{c}(\mathbf{x}, t)$ at that location $\mathbf{x}$ and time $t$.

During the flooding experiments it is possible to obtain infiltration values at the local scale by using other devices. For consistency we did not use other methods and rely on two double-ring campaigns, This implies that the only available measurements are those of $I_{c, 0}$ and $I_{c, f}$. Only a few points are available for each one of these two variables. The former was obtained at 6 spatial points and the latter at those same 6 points plus three additional ones (a total of 9).

It is worthwhile noting that double-ring tests provide a direct estimate of infiltration capacity at the scale of the 
Table 1 Experimental double ring test results performed in February 2009 (associated to $I_{c, 0}$ ) and June 2009 (associated to $I_{c, f}$ )

\begin{tabular}{llll}
\hline Location & $I_{c, 0}$ & $I_{c, f}$ & Ratio \\
\hline S1 & 0.19 & 0.18 & 0.94 \\
S2 & 2.6 & 2.1 & 0.80 \\
S3 & 2.9 & 2.5 & 0.86 \\
S4 & 3.3 & 1.1 & 0.33 \\
S5 & 12.9 & 1.2 & 0.09 \\
S6 & 12.6 & 6.3 & 0.5 \\
S7 & & 0.17 & \\
S8 & & 3.04 & \\
S9 & & 0.75 & \\
Mean & 5.74 & 2.07 & \\
Variance & 30.6 & 3.98 &
\end{tabular}

All values are expressed in $\mathrm{m} / \mathrm{d}$

device. In this case, they were representative of a small support scale $\left(\approx 0.12 \mathrm{~m}^{2}\right)$. This may have a significant influence in the geostatistical analysis, since it is important to use a method that accounts if necessary for the difference in support between the different variables involved. In Fig. 1 the "S"

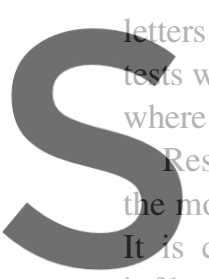
rs denote the locations whe
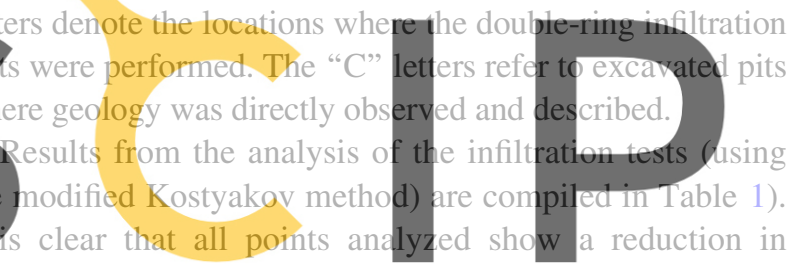

infiltration between the initial and the final stage. This reduction is larger (both in absolute and in relative terms) Register for free at https fowww scipedia.com to

\subsection{Local scale modelling}

The results of the correlation between the red band of the image presented in Fig. 1 and the logarithm of the infiltration values at $t=t_{0}$ and at $t=t_{f}$ are found to be linear (Fig. 3) according to Eqs. 4 and 5. A good linear correlation is obtained for both states of the artificial pond, with a Pearson's coefficient of $r^{2}=0.87$ for the February campaign $\left(t=t_{0}\right)$ and $r^{2}=0.89$ for the June campaign $\left(t=t_{f}\right)$.

\subsection{Experimental variograms and cross-variograms}

Field experiments are usually difficult to conduct and costly. Thus, one can typically always expect a very low number of data points, which in most cases (certainly in ours), prevents the direct estimation of the variogram of the infiltration capacity. Instead, a well behaving sampled variogram may be available for some secondary variable, $P_{v}$ in our case. Figure 4 shows the resulting two directional variograms obtained for $P_{v}$ in the principal directions. The direction of

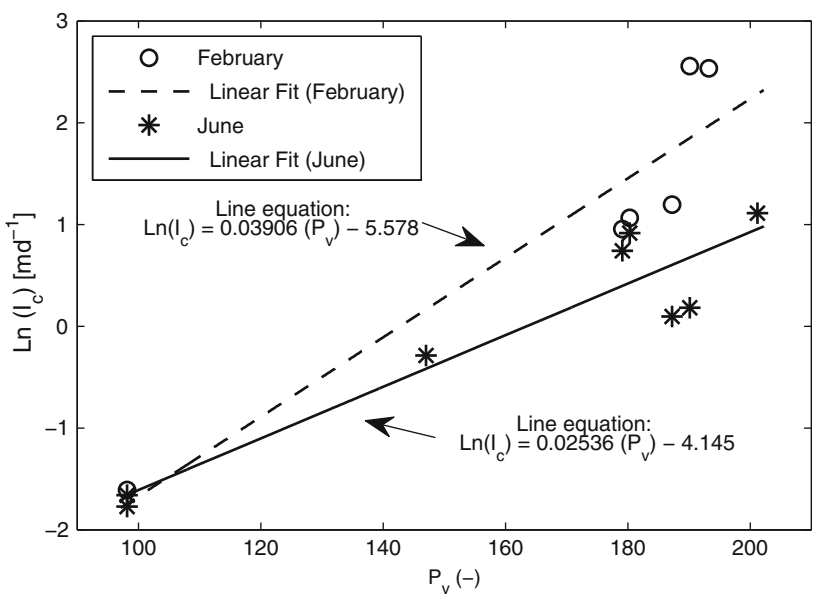

Fig. 3 Correlation between the pixel values $\left(P_{v}\right)$ from the red band of the satellite image (Fig. 1) and measured log-infiltration capacities $\left(I_{c}\right)$ at selected locations at two different campaigns. The lines show the results from linear fitting to the experimental data. The Pearson's coefficient for the dotted line (February dataset) is $r^{2}=0.87$; for the straight line (June dataset), $r^{2}=0.89$

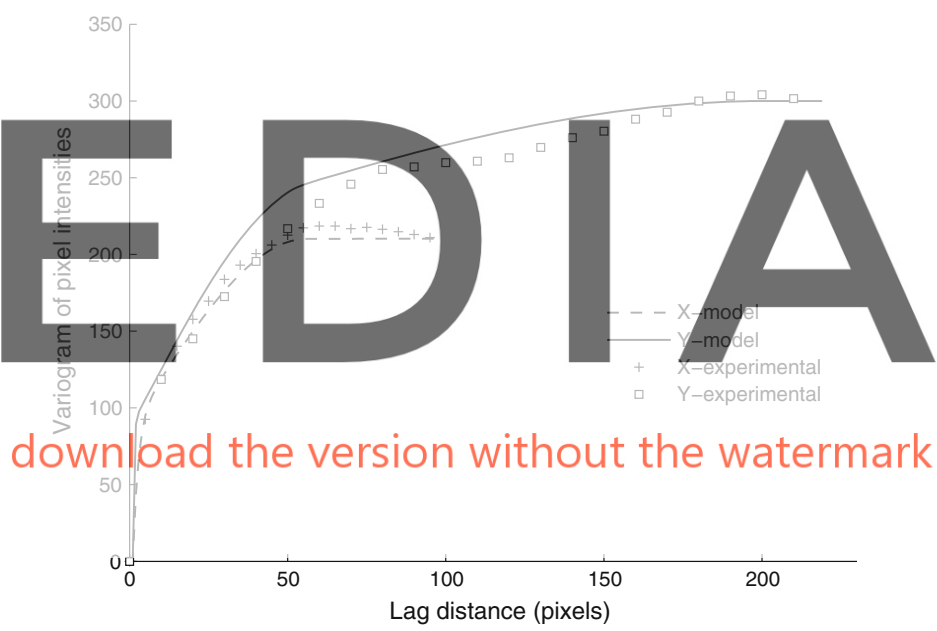

Fig. 4 Directional variograms of the pixel values in the reference image (exhaustive dataset)

maximum correlation is oriented along the $y$ axis. The model variograms show three different structures, whose combined formulation in terms of principal directions is

$$
\begin{aligned}
\gamma_{P_{v}}\left(h_{x}\right)= & 297\left[0.32 \cdot \operatorname{Gauss}\left(\frac{h_{x}}{7}\right)+0.44 \cdot \operatorname{Sph}\left(\frac{h_{x}}{92}\right)\right. \\
& \left.+0.24 \cdot \operatorname{Exp}\left(\frac{h_{x}}{400}\right)\right] \\
\gamma_{P_{v}}\left(h_{y}\right)= & 297\left[0.32 \cdot \operatorname{Gauss}\left(\frac{h_{y}}{7}\right)+0.44 \cdot \operatorname{Sph}\left(\frac{h_{y}}{68}\right)\right]
\end{aligned}
$$

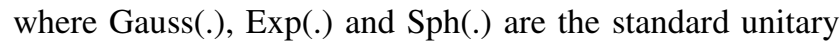
variogram models (Deutsch and Journel 1998). 


\subsection{Mapping the clogging factor}

Finally, the clogging factor $\lambda$ should also be estimated. In our case, no direct field estimates about this parameter were measured. To overcome this problem, we assumed a perfect correlation between this parameter and the initial infiltration capacity $Y_{0}$,

$Y_{\lambda}=a\left(Y_{0}\right)+b$.

The coefficients $a$ and $b$ were estimated from the temporal evolution of the integrated infiltration capacity observed during the flooding test. The theory is unclear as to whether these two parameters should be positively or negatively correlated. Thus, we explore in our site the potential range of parameters in the power law formula (12) that can lead to a fit of the observed global infiltration behavior. In particular, we analyze the sign of the coefficient $a$. We will see how this may have a strong effect in devising potential remediation strategies.

Starting from given values $a$ and $b$, the map of the $\lambda$ values is obtained with (12), and then the local infiltration in space-time is obtained from (2). Finally, the integrated infiltration is obtained with (3). The method is repeated by

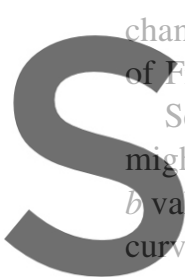
hanging the values of $a$ and $b$.

Several potential combination

b values and explore the sensitivit es to $a$. It is found that we are
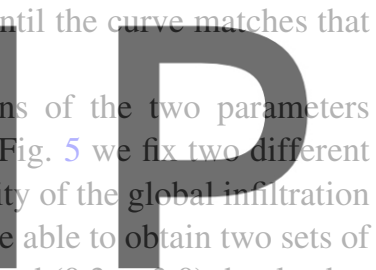

parameters $(a, b),(-0.4,-0.3)$ and $(0.3,-3.0)$ that lead to a similar fit. It can be observed that the curves are quite

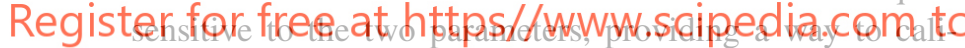
brate them. Calibration cannot be fully completed in our site since no data for intermediate times could be recorded.

As a consequence we believe that there is a need to perform short flooding tests in real sites in order to obtain real values of $\lambda$ that could be used to design an optimal management operation. This can only be obtained by performing test during the flooding period. The problem is that infiltration measurements are quite sensitive to the method used, and so it is difficult to be able to combine data coming from double-ring or seepage meters, for example.

While one can find different sets of $(a, b)$ values, the key is the sign of the $a$ parameter. Depending on this sign we will have enhanced clogging in regions of initially high infiltration capacities, or alternatively, clogging enhanced in points displaying initially small infiltration capacities. This can be seen in Fig. 6, which includes the maps corresponding to the two sets of $(a, b)$ already presented before. By construction, the maps are visually highly correlated with those of initial or final infiltration, included also in the same figure.
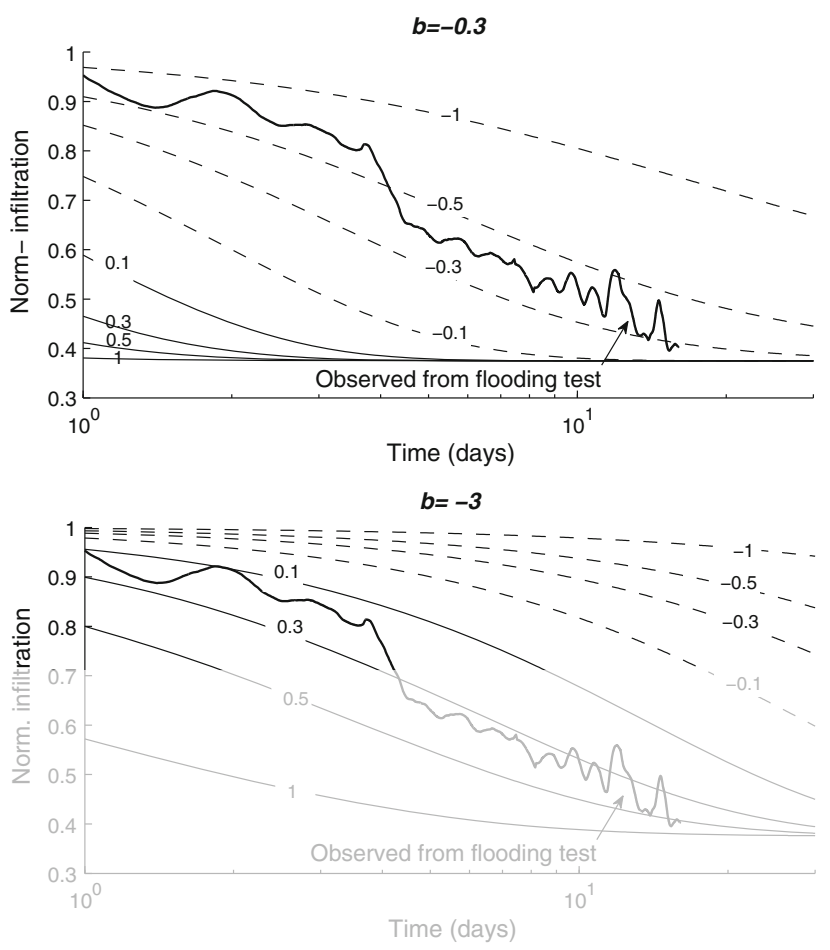

Fig. 5 Sensitivity of the correlation model between $\ln \left(I_{C}\right)$ and $\ln \left(I_{0}\right)$

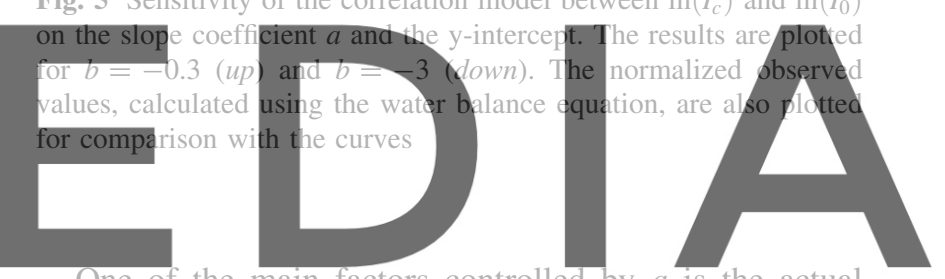

One of the main factors controlled by $a$ is the actual shape of the pdf of $\lambda$. Thus, while the two sets of param-

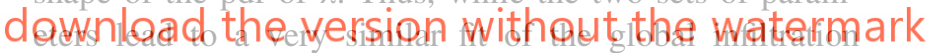

curve, $t$ actual values of $\lambda$ are very different (see Fig. 7). A direct implication is that it is not possible to derive an equivalent $\lambda$ value from the local ones capable of reproducing the full behavior. This can be observed in Fig. 8, where the evolution of infiltration with time using the harmonic, geometric and arithmetic means of the point values presented in Fig. 7 are computed. It is clear that upscaling from local values would be an error in general, and that some conditioning on real values is needed to produce a proper reproduction of the global behavior.

The evolution of the pdf of infiltration capacity with time is also dependent on the map of $\lambda$ values. This can be observed in Fig. 9, where a positive $a$ value implies a slower reduction in the infiltration values with time than a negative $a$ value. This is caused by the former leading to very small $\lambda$ values in Fig. 7 . These small values cause infiltration to be reducing slowly with time. The picture completely changes for the alternative set of parameters $(-0.4,-0.3)$ where the local $\lambda$ values are high, and thus infiltration reduces very fast with time. 


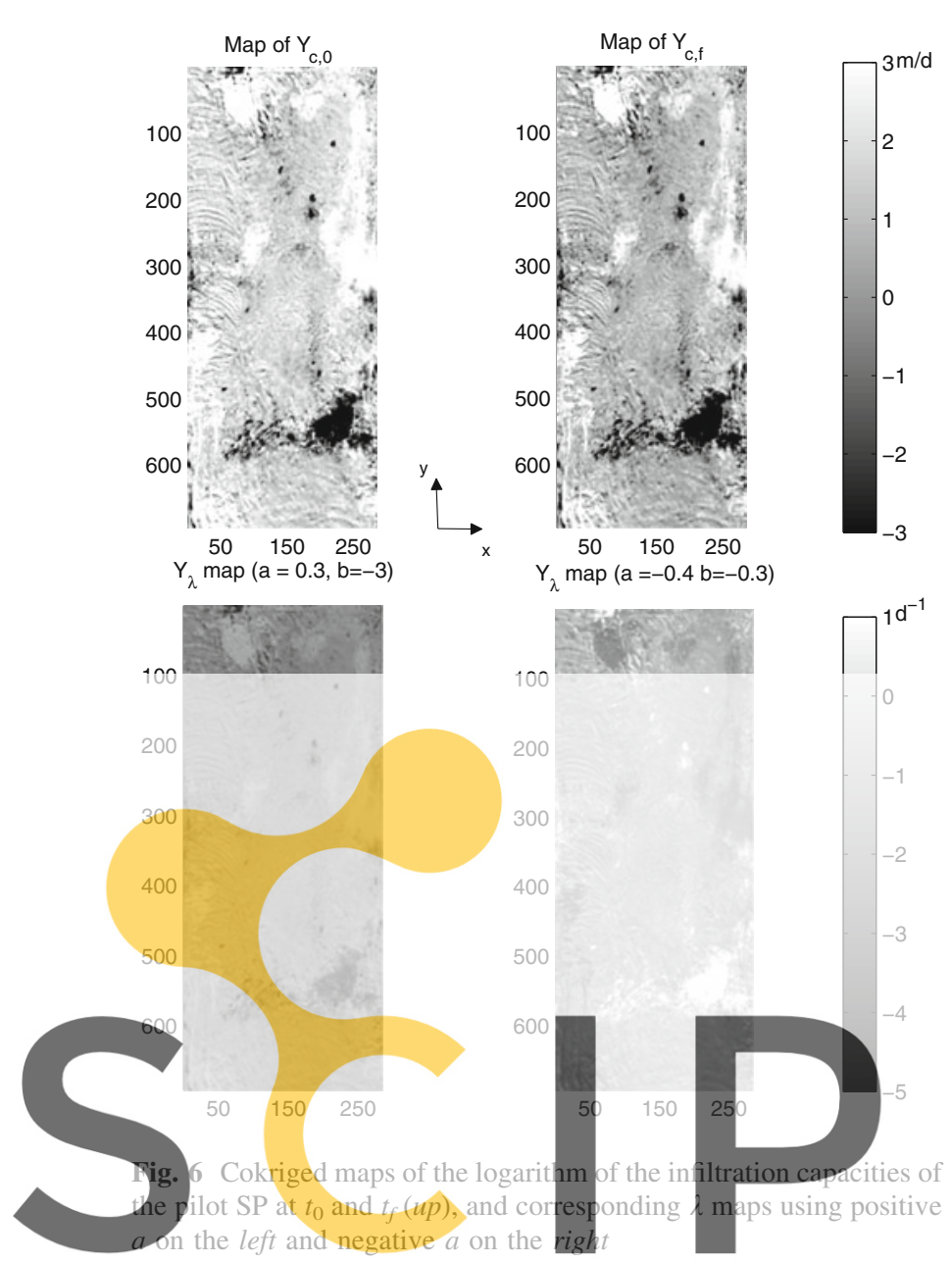

Register for free at https//www.scipedia.com to

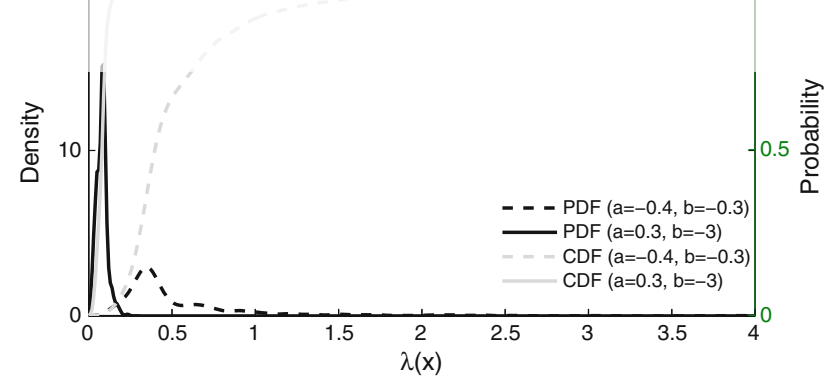

Fig. 7 Probability density function (pdf, black lines) and cumulative frequency (cdf, gray lines) of $\lambda(\mathbf{x})$ calculated using different combination of $a$ and $b$ values, and mapped in Fig. 4 (down)

These results will be significant when devising a remediation method. Notice how in Fig. 9 it is observed that for the set $(0.3,-3.0)$ all values of infiltration decrease more or less equally in time. Thus, the best alternative for remediation would be to empty the full pond and restore the initial capacity if possible. On the other hand, for the $(-0.4,-0.3)$ we observe how the reduction of infiltration is mostly produced by the fast reduction in the more permeable areas. Thus, we could devise a method that targets the initially high infiltration areas. If clogging in these points is prevented, the global infiltration will remain high for a long period of time.

\section{Conclusions}

Assessing spatio-temporal variability of soil hydraulic variables is often needed to make optimal, effective and efficient decisions in many branches of the groundwater hydrology. In systems with complex processes and in a heterogeneous geological context, such as in the case of artificial recharge practices using surface ponds (SP), the estimation of such parameters is highly uncertain. This is mainly due to scarce primary information, due to the high costs of direct field observation, due to limited accessibility to the sites or even due to partial knowledge of the physical processes involved. Lumped models are often preferable to work with due to their simplicity and versatility, and secondary information could provide reliable supporting data to be used for mapping purposes of pri-

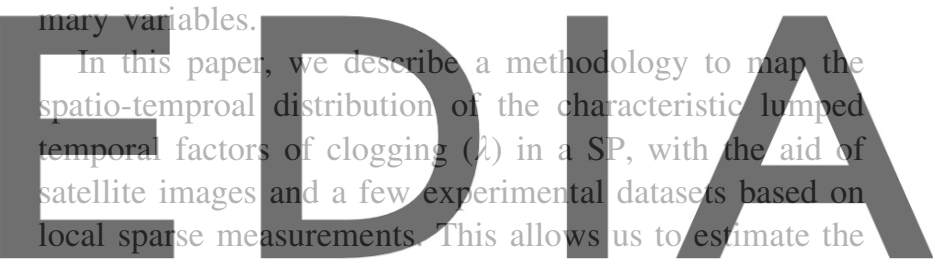

spatio-temporal variability of the infiltration capacities of the topsoil. This potentially allows managers to find optid mwntoad the versipn without the waterimark

the effect of clogging without having to operate the full facility and to make educated decisions that might mitigate the failure in O\&M operations in an SP.

As a case study, we applied this method to a pilot site in Spain. Although the developed model introduces some simple hypotheses and simplifications in this illustrative example, we showed that we were able to map the evolution of local infiltration with time. To validate the method, we compared the measured total infiltration capacities at the SP scale with the ones calculated by integration of calculated local values using a geostatistical-physicallymixed approach. Numerical results satisfactorily agree with the observations, accounting for the multiple necessary approximations we assumed.

It is found that arguably the most significant parameter is the sign of the $a$ parameter in the power law model relating $\lambda$ and the initial infiltration. Depending on this sign it is possible to see the practical relevance of designing a remediation method that targets only parts of the domain (acting on the high infiltrating areas during operation), or else it is better to use the classical approach of treatment 
Fig. 8 Evolution of the normalized mean infiltration capacity of the pond evaluated using different methods, versus the observed values and the equivalent solution using the effective $\lambda^{e}=0.17$ day $^{-1}$. The numerical solutions (marked with line and symbols style) are obtained by spatial average of local values calculated using the model. Analytical solutions using the geometrical (straight line), harmonic (dot-point line) and arithmetic (dot-dot) averaging of $\lambda(x)$ as effective decay rate are also reported for comparison purposes reference local infiltration
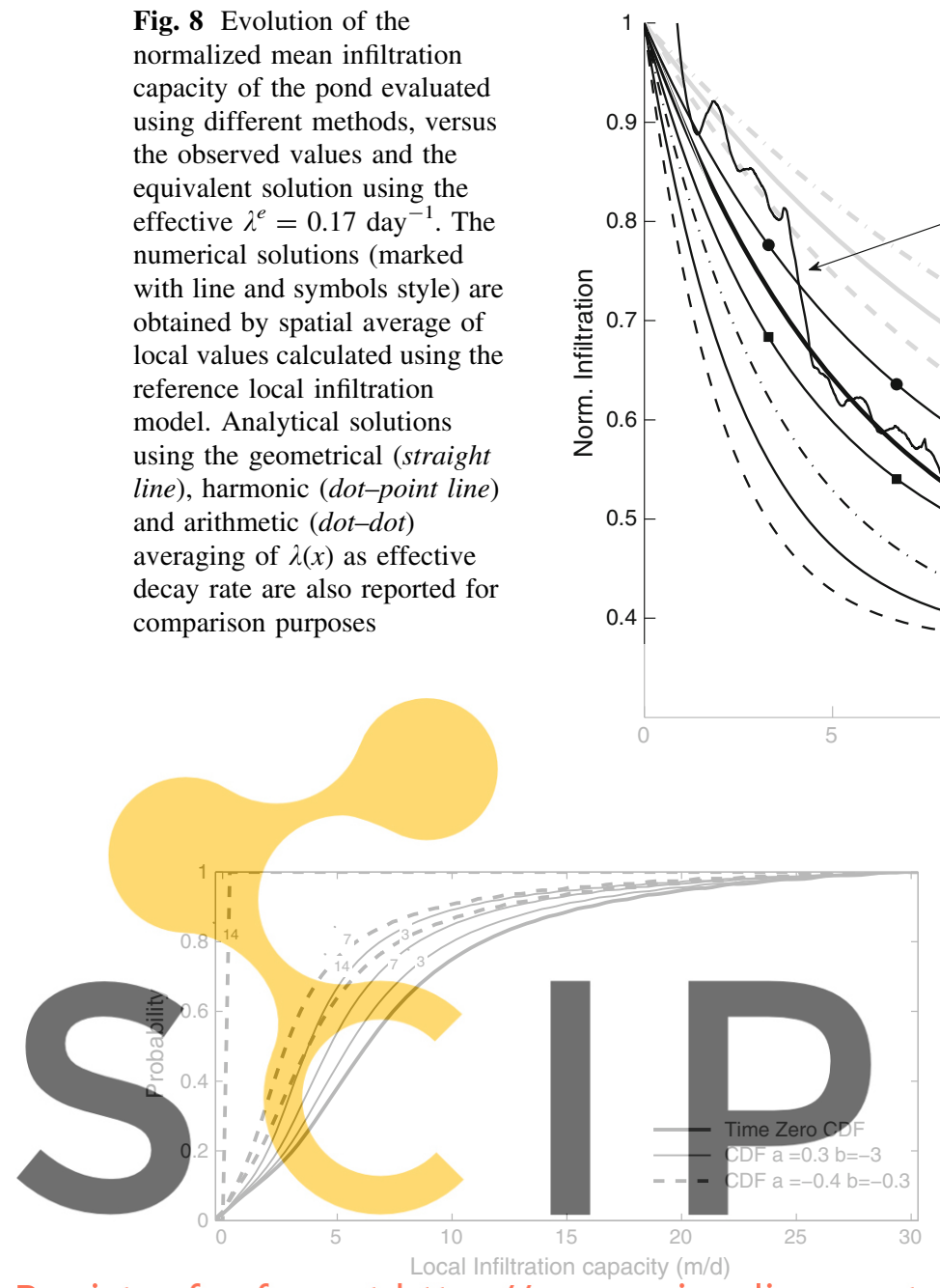

Register for free at https//www.scipedia.com to d Fig. 9 Evolution of the probability of local infiltration capacity
values in the pond at different times (the tags express the days elapsed after the flooding test began) using two possible combination of relationships between $\lambda$ and the initial infiltration capacity

after emptying the facility. This alternative might have significant impact in managing an SP site.

Acknowledgments This project was financially by the Spanish Ministry of Science and Innovation via the CONSOLIDER-Ingenio 2010 (CSD2009-00065), RARA-AVIS (CGL2009-11114) and HEROS (CGL2007-66748) projects. DP would like to further acknowledge the Spanish government for funding through the FPU scholarship programme (Formation of University Lecturers).

\section{References}

Almeida A, Journel A (1996) Joint simulation of multiple variables with Markov-type coregionalization model. Math Geol 26(5): $565-588$

Barahona-Palomo M, Pedretti D, Sanchez-Vila X (2010) Infiltration tests at the Sant Vicenç dels Horts artificial recharge experimental site. In: EGU General Assembly 2010 (ed) Geophysical Research Abstracts, EGU2010-5326, vol 12

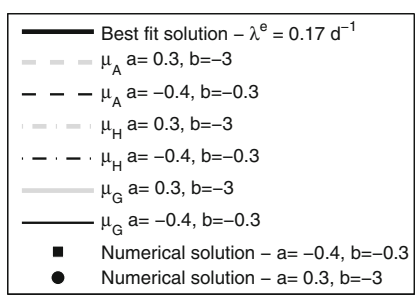

Observed from flooding test

- Numerical solution $-\mathrm{a}=0.3, \mathrm{~b}=-3$

Baveye P, Vandevivere P, Hoyle BL, de Leo PC, de Lozada Sanchez D (1998) Environmental impact and mechanisms of the biological clogging of saturated soils and aquifer materials. Crit Rev

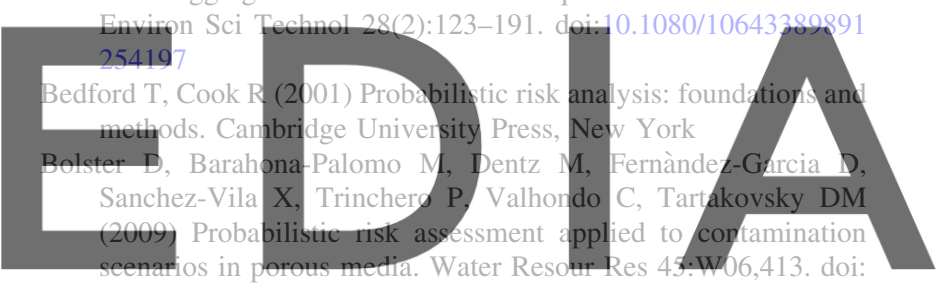

10.1029/2008WR007.551

Bouwer H (1999) Artificial recharge of groundwater: system design,

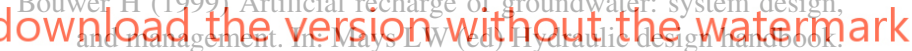
McGraw-Hill, New York. pp 24.1-24.44

Bouwer H (2002) Artificial recharge of groundwater: hydrogeology and engineering. Hydrogeol J. doi:10.1007/s10040-001-0182-4

Carman P (1938) The determination of the specific surface of powders. J Soc Chem Ind Trans 57:225

Carrera J, Vazquez-Sune E, Abarca E, Capino B, Gamez D, Simo A, Ninerola J, Queralt E (2005) El baix Llobregat. Historia i actualitat ambiental d'un riu, chap Les aigues subterranies del Baix Llobregat. pp 72-92

Chica-Olmo M, Abarca-Hernandez F (2000) Computing geostatistical image texture for remotely sensed data classification. Comput Geosci 26:373-383

Civan F (2007) Temperature effect on power for particle detachment from pore wall described by an Arrhenius-type equation. Trans Porous Med 67(2):329-334

Civan F (2010) Non-isothermal permeability impairment by fines migration and deposition in porous media including dispersive transport. Transp Porous Med. doi:10.1007/s11.242-010-9557-0

Clement TP, Hooker BS, Skeen RS (1996) Macroscopic models for predicting changes in saturated porous media properties caused by microbial growth. Groundwater 34(5):934-942

Cunningham AB, Characklis WG, Abedeen F, Crawford D (1991) Influence of biofilm accumulation on porous media hydrodynamics. Environ Sci Technol 25:1305-1311

Custodio E (2002) Aquifer overexploitation: what does it mean? Hydrogeol J 10:254-277. doi:10.1007/s10040-002-0188-6 
de Barros FPJ, Rubin Y (2008) A risk-driven approach for subsurface site characterization. Water Resour Res 58:W01,414. doi:10.1029/ 2007WR006081

Deutsch C, Journel A (1998) Gslib: geostatistical software library and user's guide. Tech. rep., Oxford University Press, New York

Gooverts P (1997) Geostatistics for environmental applications. Oxford University Press, USA

Granger R (2000) Satellite-derived estimates of evapotranspiration in the gediz basin. J Hydrol 229:70-76

Greskowiak J, Prommer H, Massmann G, Johnston CD, Nützmann G, Pekdeger A (2005) The impact of variable saturated conditions on the hydrochemistry during artificial recharge of groundwater-a field study. Appl Geochem 20:1409-1426

Guin JA (1972) Clogging of nonuniform filter media. Ind Eng Chem Fundam 11(3):345-349. doi:10.1021/1160043a010

Hazen A (1882) Some physical properties of sands and gravels, with special reference to their use in filtration. 24th Annual Rep, Massachusetts State Board of Health. Pub Doc 34:539-556

Hoffmann A, Gunkel G (2010) Bank filtration in the sandy littoral zone of Lake Tegel (Berlin): Structure and dynamics of the biological active filter zone and clogging processes. Limnologica-Ecology and Management of Inland Waters In Press, Corrected Proof. doi:10.1016/j.limno.2009.12.003, http://www. sciencedirect.com/science/article/B7GX1-4YK88XC-1/2/5b4d8b5 a1ed550ecf8d24cc17b40d993

Iwasaki T (1937) Some notes on sand filtration. J Am Water Works Assoc 29:1597-1602

Journel A (1999) Markov models for crosscovariances. Math Geol 31(8):955-964

Kim JW, Choi H, Pachepsky YA (2010) Biofilm morphology as related to the porous media clogging. Water Res 44(4): 1193-1201. doi:10.1016/j.watres.2009.05.049, http://www.science direct.com/science/article/B6V73-4WNGW5F-1/2/ 0a7f4de465f62adf795d4bbbc3ea3dab, transport and Fate of Colloids and Microbes in Granular Aqueous Environments

Kozeny J (1927) Uber Kapillare Leitung des Wassers im Boden. Sitzungsber Akad Wiss Wien 136:271-306

Krzysztofowicz R (2001) The case for probabilistic forecasting in hydrology. J Hydrol 249:2-9

Management of aquifer recharge and subsurface storage (2003) Netherlands National Committee-International Association of Hydrogeology, No. 4. NNCIAH Publication

Masetti M, Sterlacchini S, Ballabio C, Sorichetta A, Poli S (2009) Influence of threshold value in the use of statistical methods for groundwater vulnerability assessment. Sci Total Environ 407(12): 3836-3846. doi:0.1016/j.scitotenv.2009.01.055, http://www.science direct.com/science/article/B6V78-4W0R3BY-1/2/ 80d0bac534dd772455927723f038fd98, thematic Issue-BioMicroWorld Conference

Milewskia A, Sultana M, Yanb E, Beckera R, Abdeldayemc A, Solimand F, Gelil K (2009) A remote sensing solution for estimating runoff and recharge in arid environments. J Hydrol 373(1-2):1-14

Monod J, Wyman J, Changeux JP (1965) On the nature of allosteric transitions: a plausible model. J Mol Biol 12:88-118

Okubo T, Matsumoto J (1979) Effect of infiltration rate on biological clogging and water quality changes during artificial recharge. Water Resour Res 15(6):1536-1542. doi:10.1029/WR015i006 p01536

Olsthoorn T (1982) The clogging of recharge wells, main subjects. Tech. rep., Working group on recharge wells. Riswijk, The Netherlands. $136 \mathrm{pp}$

Pedretti D, Barahona-Palomo $\mathrm{M}$, Bolster D, Fernàndez-Garcia D, Sanchez-Vila X (2010) Spatial assessment of infiltration capacity of soils for artificial recharge practices using Google Earth images. Proceedings of the GeoENV Conference, Ghent University, Ghent (Belgium)

Pedretti D, Barahona-Palomo M, Bolster D, Sanchez-Vila X, Fernàndez-Garcia $\mathrm{D}$, Tartakovsky $\mathrm{D}$ (under review) Probabilistic analysis of maintenance and operation of artificial recharge ponds. Adv Water Resour

Perez-Paricio A, Carrera J (1999) Clogging handbook. Tech. rep., Final report, EU project on Artificial Recharge of Groundwater

Scanlon BR, Keese KE, Flint AL, Flint LE, Gaye GB, Edmunds WM, Simmers I (2006) Global synthesis of groundwater recharge in semiarid and arid regions. Hydrol Process 20:3335-3370

Smith R (1972) The infiltration envelope: results from a theoretical infiltrometer. J Hydrol 17:1-21

Tartakovsky DM (2007) Probabilistic risk analysis in subsurface hydrology. Geophys Res Lett 34:L05,404. doi:10.1029/2007G L029.245

Tartakovsky DM, Winter CL (2008) Uncertain future of hydrogeology. ASCE J Hydrol Eng 13(1):37-39

Tien C, Payatakes AC (1979) Advances in deep bed filtration. AIChE J 25(5):737-759

Vandevivere P, Baveye P (1992) Relationship between transport of bacteria and their clogging efficiency in sand columns. Appl Environ Microbiol 58(8):2523-2530

Vandevivere P, Baveye P, de Lozada DS, DeLeo P (1995) Microbial clogging of saturated soils and aquifer materials: evaluation of mathematical models. Water Resour Res 31(9):2173-2180

Zamani A, Maini B (2009) Flow of dispersed particles through porous media-deep bed filtration. J Pet Sci Eng 69:71-88 